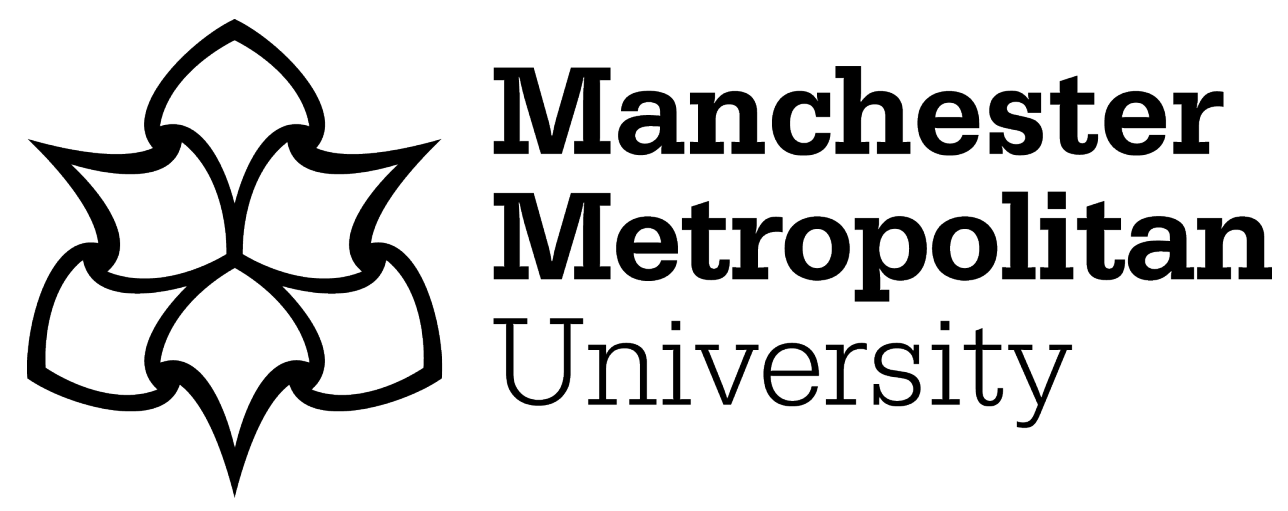

Rogers, M and Ahmed, A ORCID logoORCID: https://orcid.org/0000-00026164-0656 (2017) Interrogating trans and sexual identities through the conceptual lens of translocational positionality. Sociological Research Online, 22 (1). pp. 81-94.

Downloaded from: https://e-space.mmu.ac.uk/625888/

Version: Accepted Version

Publisher: Sage

DOI: https://doi.org/10.5153/sro.4169

Please cite the published version 


\title{
Interrogating Trans and Sexual Identities Through the Conceptual Lens of Translocational Positionality
}

\author{
by Michaela Rogers and Anya Ahmed \\ University of Salford; University of Salford
}

Sociological Research Online, 22 (1), 4

<http://www.socresonline.org.uk/22/1/4.html>

DOI: $10.5153 /$ sro.4169

Received: 26 Jun 2016 | Accepted: 28 Dec 2016 I Published: 28 Feb 2017

\begin{abstract}
This article explores the confluence of trans identity and sexuality drawing on the concept of translocational positionality. In this discussion, a broad spectrum of gendered positionalities incorporates trans identity which, in turn, acknowledges normative male and female identities as well as non-binary ones. It is also recognised, however, that trans identity overlaps with other positionalities (pertaining to sexuality, for example) to shape social location. In seeking to understand subject positions, a translocational lens acknowledges the contextuality and temporality of social categories to offer an analysis which recognises the overlaps and differentials of co-existing positionalities. This approach enables an analysis which explores how macro, or structural, contexts shape agency (at the micro-level) and also how both are mediated by trans people's multiple and shifting positionalities. In this framing, positionality represents a meso layer between structure and agency. Four case studies are presented using data from a qualitative study which explored trans people's experiences of family, intimacy and domestic abuse. We offer an original contribution to the emerging knowledge-base on trans sexuality by presenting data from four case studies. We do so whilst innovatively applying the conceptual lens of translocational positionality to an analysis which considers macro, meso and micro levels of influence.
\end{abstract}

Keywords: Trans/transgender, Gender Diversity, Translocational Positionality, Identity, Sexuality, Sexual Orientation

\section{Introduction}

1.1 Contemporary culture shapes the terrain for the production and privileging of gendered identities, or positionalities (Jackson 2006). Positionality is a useful concept which encourages an analysis of people and lived experience not in terms of fixed identities, but by an individual's location across shifting networks of relationships (Anthias 2002). In relation to gendered positionality, it has been argued that this is intelligible only within a hierarchical, heteronormative matrix of social life (Butler 1990; Schilt and Westerbrook 2009). In this paper, heteronormativity refers to the way in which socio-cultural life is based upon fixed understandings of gender as binary (male/female) which is then enacted through heterosexuality, marriage and procreation (Warner 1991; Schilt and Westerbrook 2009). The phenomenon of trans identity and practice disrupts this framework to offer an alternative. Indeed, since the 1970s there has been a slow, but steady, increase in the visibility of trans people which in part has resulted from the activism of social movements and academic scholarship (Stone 1987; Hines 2007; Davy 2011). Notwithstanding, gaps remain in terms of our understanding of trans people's subjectivities and positionalities. Therefore, this paper offers an original contribution as there is a value in investigatory work which employs a socio-cultural lens instead of a medical approach, upon which there exists a more substantial body of literature (Dargie et al. 2014).

The discussion presented here integrates narratives taken from a study which explored trans people's daily negotiations within their intimate and familial relationships as well as their experiences of domestic abuse. The selected narratives illustrate how positionality moves across a gender spectrum oscillating between, 
transgressing and transcending binary and normative conceptions of gender (Ekins and King 2006). The narratives also demonstrate how trans identity overlaps with other positionalities (in this case, sexuality) to shape subjectivity. In this analyses, a translocational lens acknowledges the context and temporality of social categorisation. This is reflected in the study's narrative methodology as in narrative thinking, context is ever present' (Clandinin and Connelly 2000: 32). As such, this paper draws attention to material and cultural contexts (for example, the impact of heteronormativity and the public/private divide) to explore the diverse influences on and the convergences of gender and sexuality which serve to mobilise or constrain trans identity (and to promote or counter heteronormative ideals). In this way, the movement, or translocation, of positioning acts as a meso layer between structure and agency (Ahmed 2015). So, the potential of translocational positionality as a conceptual lens is elucidated throughout to highlight how it facilitates an analysis of personal agency whilst also pointing to the structural influence of gender and sexual normativity.

The article is divided into three sections and begins by providing a theoretical overview of the authors' approach to gender, trans and sexual identity. This is followed by an exposition of translocational positionality which is drawn upon in order to propose 'an intersectional framing [of trans] which centres on social location and translocation' (Anthias 2012: 122). The second section sets out the methodology for the study from which narrative data is drawn. Next, four participants are presented as case studies. Each participant was chosen to acknowledge the operation of the meso layer in facilitating the fluidity of gender and sexuality. Each case study is analysed through the conceptual lens of translocational positionality to illustrate agency, but also to contextualise the constraining influence of social structures and institutions. The paper ends with some concluding thoughts about the value of translocational positionality as a conceptual device.

\section{Contesting the binary: trans and non-binary gender}

2.1 A more detailed exposition of gender and trans is apposite here as these concepts are central to the discussion offered in this paper. At a structural level, gender results from cultural processes which order and organise people according to their bodies and behaviours. These processes are undergirded by expectations and assumptions in connection to sex (as a biological imperative). Through the cultural process of gendering (or misgendering), gender identity develops, operating to facilitate:

one's sense of self as a gendered person (for example, as man, woman, both, neither, or some other configuration of gender). A person's gender identity may or may not match the sex assigned at birth or current legal sex... it may or may not conform to conventional expectations of maleness or femaleness, including expectations of what a man's or woman's body looks like. (Enke 2012: 18)

2.2 Throughout the last few decades, feminist analyses have resulted in gender being theorised as a social construct (Kessler and McKenna 1978; Fausto-Sterling 2000), as performative (Butler 1990, 2004) and, simply, as something that we 'do' (West and Zimmerman 2009). Most feminist work on gender and identity, however, is situated against a landscape where gender is dichotomous and stable, incorporating the pairings of male/female and masculine/feminine. This landscape, which includes dominant discourses, offers a narrow range of meanings for gendered identity, embodiment and practice. Moreover, the freely available, dominant and normative discourses are mostly androcentric and built on notions of gender as hierarchical where man/male is superior to woman/female (Talbot 2010). As the hierarchical nature and elitism of such discourse privileges men and oppresses women, it also marginalises and silences individuals or communities whose identity, practice and/or aesthetics do not conform to gender norms; including those who identify as trans (Pershai 2006).

2.3 Despite the predominance of feminist analyses of binary and normative gender, a growing body of work can be found which interrogates gendered life outside this framework using the lens of trans subjectivity (Hines 2007, 2013; Davy 2011; Rogers 2013, 2016a, 2016b). Moreover, trans identity, embodiment and practice disrupts conceptions of binary gender as fixed and natural, and in doing so problematises some of the essentialised work of the past few decades (see also Butler 1990, 2004; Fausto-Sterling 2000). In addition, through the growing body of literature on trans phenomena a new binary opposition has emerged, that of cisgender and trans (Enke 2012). The term 'cisgender' derives from the Latin prefix 'cis' meaning on the same side or remaining with the same orientation. The term 'cisgender' (and its shorthand 'cis') helps to delineate 'non-trans' people (those whose gender is congruent with that which was ascribed at birth) (Enke 2012).

2.4 Whilst some authors use 'trans' and 'transgender' interchangeably, throughout this paper the authors employ 'trans' as an umbrella term to capture a broad range of positionalities which sit within, across or outside of a gender spectrum (Ekins and King 2006; Monro 2007; Enke 2012). Wilchins (2004: 26) offers a concise definition of trans/transgender contextualised through both temporary and permanent embodiment practices, as 
trans identity refers to: 'people who cross sexes by changing their bodies (transsexual) and those who cross genders by changing their clothing, behaviour and appearance (transgender)'. Distinguishing between the terms 'transgender' and 'transsexual', however, raises a semantic challenge. The first term implies a primary focus on gender and the latter on sexuality; a misnomer highlighted by some transsexuals who bring attention to the claim that 'transsexuality' concerns gender, not sexuality (Monro and Warren 2004). The distinction between gender (a construct) and sex (a biological category) is significant as transsexual narratives often incorporate 'the wrong body' trope, depicting the inner self (gender identity) as separate to and dissonant from the corporeal, sexed body (Prosser 1998; Serano 2007). This dissonance is defined within diagnostic frameworks as 'gender identity disorder' or 'gender dysphoria'. As suggested by Wilchins then, transsexualism refers to the identification with normative taxonomies of gender within the male/female binary and can incorporate the desire to permanently reassign the sexed body. It must be noted, however, that not all transsexuals pursue gender reassignment, nor do they always identify within the confines of the gender binary.

Acknowledging heterogeneity and the increasing recognition of trans as a social category, Whittle (2006:

xi) claims that 'a trans identity is now available almost anywhere, to anyone who does not feel comfortable in the gender role they were attributed with at birth'. As a social category trans is multifaceted and an array of identities include: transsexual man/transsexual woman; trans man/trans woman; transgender man/woman; MTF/FTM; queer; genderqueer; butch/femme; and crossdresser. It is, however, hard to capture the heterogeneity of trans as even in studies which offer a comparatively comprehensive range of gender identity options to select from, lantaffi and Bockting (2011) found that $29.5 \%$ of 1,229 respondents to an online survey chose 'other' when reporting their gender. As such, the discussion so far has pointed to the opaque and multifarious nature of terminology and discourse surrounding trans identity and practice.

The intersection of trans and sexual identity creates an additional layer of complexity to gender/sexuality discourse. Indeed, independently both are complex areas of inquiry and some have argued to partition these debates, particularly as sexuality has been neglected or positioned as secondary to gender (Sedgwick 1990). Conversely, trans identity and practice can reaffirm the interconnectedness and mutuality of gender and sexuality by translocating, or travelling across, between and beyond existing boundaries of male/female and heterosexual/homosexual (Ekins and King 2006). Further, Steinbock (2014) draws attention to how the diagnostic protocols surrounding gender reassignment reflect this mutuality as the sexological histories that prefigure the sexual in a transsexual diagnosis (gender identity disorder, gender dysphoria) fasten desire onto the transition itself' (2014: 156). Steinbock highlights the ways in which, within this framework, medical practitioners seek to illicit statements from transsexuals about the disgust one feels about one's sexed embodiment with the consequence of reinforcing the interrelationship between gender and sexuality (Steinbock 2014). As such, the medical concept of transsexuality (and its connection to gender identity disorder or gender dysphoria) 'either overtly represses or denies sexuality as a factor in trans experience, or explicitly understands transitioning as originating in a hypersexuality' (Davy and Steinbock 2011: 266).

2.7 Bockting et al. (2009) argued that there are signs to suggest the emergence of a positively-oriented trans sexuality which centres on the erotic appeal of trans identity, trans bodily aesthetics, sexual behaviour and experience. Indeed a range of literature and media platforms are increasingly found which explore and celebrate trans sexuality. For example, Davy and Steinbock (2011) explore the means by which pornography represents a social space for trans people to explore and produce sexual embodiment moving beyond the triad of hetero/homo/bisexuality whilst also rejecting the dominant cultural and medical theorisations on trans sexuality. In addition, there is a growing number of studies which explore the sexual quality of life in relation to trans and gender reassignment surgery (see, for example, Wierckx et al. 2011, and Bartolucci et al. 2015). Overall, there is, however, a dearth of literature which examines the relationship between trans and sexuality (Pfeffer 2014). In addition, there is no consensus within the trans community about the significance of the interconnection of gender identity and sexuality. For example, in a study by Nagoshi et al. (2012) some trans participants viewed both as inherently separate, whilst others articulated their orientation and gender identity as mutually influencing one another. This mutuality is reflected in this paper as most participants in the study proffered self-identifications that consolidated the relationship between their gender and sexual identities, but in accord with Davy and Steinbock's paradigm, trans sexuality is articulated through an 'ontology of desire as an aesthetic force that is endless and rhizomatic rather than adhering to an ontology of 'being' in any static sense' (Davy and Steinbock 2011: 268).

\section{Translocational positionality: a conceptual tool}

3.1 The notion of positionality refers to 'placement within a set of relations' as well as 'practices that implicate identification and 'performativity' or action' (Anthias 2002: 501). Anthias (2002) further claims that 
positionality is 'an intermediate concept between objectivism and subjectivism, inhabiting a space between social constructionism and approaches that stress agency' (2002: 502). However, the notion of positionality is not reducible to this. It combines social positioning (as process, practice or action) as well as social position (as outcome); positionality, therefore, pertains to both structure and agency. So an analysis of positionality should consider the practices and performative nature of positionalities as well as the systemic and intersubjective conditions of these systems. Positionality is also a useful conceptual tool to understand the meso level between structure and agency, since it allows for a consideration of the processes involved in identity construction, thus taking account of agency within the context of wider social structures. Translocational positionality is also shaped by the melding of multiple social positions, resulting in such locations becoming different and more than they 'are' (Ahmed 2015).

3.2 Processes of identification are indisputably integral to this analysis with a particular focus on two; those of similarity and difference. The processes of similarity and difference denote boundaries and belonging (and its opposite, non-belonging). These boundaries and the processes of belonging are not discrete, nor independent, as commenting on the interplay of similarity and difference, Jenkins (2014: 22) notes that 'neither makes sense without the other, and identification requires both'. In the case of trans identity, the processes of similarity and difference call upon an understanding of gender as a binary category or, in relation to non-binary gender, as something that is Other. Jenkins offers a framework for understanding, what he terms, 'the internal and external moments of the dialectic of identification' (2000: 7). This embeds an understanding of two iterative and dynamic practices which are critical to the mechanics of similarity and difference: how we identify ourselves (internal individual/group identification) and how others identify us (external ascription). Identification then, is relational and emergent as well as culturally and socially situated. Therefore, whilst having analytic value, identity does not have a predetermined or fixed essence (Anthias 2002; Ahmed 2015). Furthermore, in terms of belonging, or not belonging, this entails more than identifying with a particular community or group, it relies on being accepted by others as a member of that community or group (Cohen 1982; May 2013). There are different social locations from which belonging is imagined and constructed. Such social locations can be understood as 'translocations' of social positions, social divisions and identities (Anthias 2008; Ahmed 2015). The possibilities and restrictions resulting from the processes of individual identification and collective belonging are particularly germane for trans people.

3.3 Pointing to structure and agency, Pini (2004: 171) notes how identities and subjectivities are constituted 'across a range of different discourses, often competing and inconsistent, and constructed not just by us, but for us'. Stanley and Billig (2004: 160) consider agency when commenting that 'identity claims can be part of narrative stories, for in making claims about the self speakers will often tell stories'. Stanley and Billig treat identity as discursive and a situated construct (as opposed to an internal state) which can be achieved through narrative practice. As the intelligibility of identity relies on social categorisation, the process of positioning one's identity (or identities) within narrative relies on the availability of a range of categories and discourses. This process is iterative and multi-dimensional as through discursive practice individuals have the potential to locate themselves in multiple and overlapping positions simultaneously. As such, Anthias $(2002,2012)$ proposes that the concept of translocational positionality has value in projects which explore social identities, hierarchies and mobility in relation to context, marginalisation, community and belonging. A translocational lens is:

a tool for analysing positions and outcomes produced through the intersections of different social structures and processes, including transnational ones, giving importance to the broader social context and to temporality. (Anthias 2012: 130)

3.4 This suggests a focus on the processes of social location relative to context, time and meaning as embedded in hierarchical relations. This formation inevitably involves shifts, ambiguities and contradictions. In terms of the desire to understand how people construct their identities and experiences, translocational positionality has epistemological value as it is concerned with these processes, but on a micro-level with performance and practice (Holstein and Gubrium 2000). Interrogating the performative in narrative helps to illustrate how people represent their identities, lives and experiences (Ahmed 2015). A translocated framing, in addition, serves as a reminder that context and temporality are influential as people can present themselves differently in various settings and these performances can have different meanings for different actors: the narrator and the audience (Temple 2001).

\section{Methods}

4.1 The study employed a qualitative design incorporating narrative interviews. The narratives contained accounts about trans people's negotiations of personal life in relation to social, intimate and familial relationships 
and within the context of domestic abuse. Bold (2012: 16) valorises narrative in qualitative research asserting that 'narratives necessarily tell of human lives, reflect human interest and support our sense-making processes'.

Storytelling results in the 'narrated subject' (Doucet and Mauthner 2008) and the process of constructing identity through narrative practice points to the interplay between agency and structure (Hubbard 2000; Doucet and Mauthner 2008: 399). Noting the epistemological and temporal limits of working with personal narratives, Bold contends that narrative methods do not facilitate 'a search for truth but an acknowledgement of personal experiences as recounted at that moment in time' (Bold 2012: 122). In this context, interviews are 'narrative occasions' which produce a subjective account which is contextual and situated in time and space (Riessman 2008: 23).

The recruitment strategy included various means including public engagement activities (for example, direct contact with trans support groups) and via a virtual presence. The sensitive nature of the topic demanded stringent ethical practices (McClennen 2003). Moreover, acknowledging power within the researcher/researched relationship, as well as the researcher's cisgender and heterosexual positionality, the following principal was adopted:

to engage in LGBTQ research is to embrace and question fluid identity positions and to be committed to openness... perhaps, most importantly researchers need to be self-reflexive, linking knowledge and understanding gained to action taken to give LGBTQ persons presence and place in education and other communities where they can be visible and proud, respected and valued. (Grace et al. 2006: 340)

4.3 Interviews were held with a total of fifteen participants who identified across the gender spectrum and people self-identified as: trans women, pre/post-operative transsexual women, women with transsexual histories ( $n=11)$; trans male $(n=3)$; and as genderqueer $(n=3)$. Some individuals claimed multiple identities (for example, as 'trans male/genderqueer'). This paper utilises participants' self-identifications in order to maintain integrity in the analysis and reporting of narrative data. The ages of participants started at 21 with the oldest at 70 years of age. Socio-economic backgrounds varied, but most participants were from low to lower-middle income families. The majority of participants were white British but two had a non-British background.

4.4 Starting with the notion that narratives are interpretive and require interpretation (Riessman 2008; Ahmed 2013), the analytic approach was to remain grounded in the worldview of participants exploring how each constructed meanings about their experiences in the world (Doucet and Mauthner 2008: 399). Therefore, each transcript was coded using an interpretive approach, the Listening Guide, as a framework for analysis (Doucet and Mauthner 2008). This required several readings of the narrative data in order to isolate specific voices in association with different levels of influence. For example, this occurred in relation to: micro (personal) contexts (in connection to familial and intimate relationships) and macro, or structural, influences (such as gender and social norms). The Listening Guide also demands a reflexive reading where reflexivity involves 'a dialogue between multiple narrator and audience voices, all performing selves, which are brought into mobile, temporary alliances that then dissolve and reform, repeating themselves but never exactly' (Squire et al. 2014: 30). The Listening Guide reminds the researcher to remain alert to the co-constructed nature of the narrative; the text is produced through the interaction of the storyteller (the participant) and the audience (the researcher).

Consequently, a re-examination of the analysed data has facilitated an extended analysis. Conducting secondary analysis of qualitative data is now a widely recognised methodology involving a refocus on interview data with the intention of extending the analytical depth of the original work (Corti et al. 2005; Thorne 1994; Ahmed and Hall 2016; Ahmed and Rogers 2016). Secondary narrative analysis (Elliot et al. 2015; Heaton 2008) is also useful to revisit key themes within contemporary theoretical frameworks. Here, we are using secondary analysis to revisit narrative interview data to offer important new insights using the conceptual lens of translocational positionality in relation to trans and sexual identities. Therefore, through re-analysis, we provide alternative understandings of the narrative data. Four case studies have been chosen purposively as a range of cases to demonstrate variation (Shaw and Holland 2014) in terms of the gender/sexuality spectrum but also as each illustrates the processes and performativity of trans people's gender and sexual positionality. The cases were purposefully selected as each uniquely demonstrates the ways in which positionality acts as a meso layer between structure and agency.

\section{Findings and discussion: positions of trans/sexuality}

5.1 The narratives presented here - of Marianna, Mary, Max and Rachel - bring attention to the complexity of gender and sexual identity within the context of the gender binary, trans or non-binary positionality and subjectivity. The discussion adds to the dearth of literature which currently explores the intersection of these 


\section{Marianna}

Marianna (trans woman, aged 41) was recovering from gender reassignment surgery at the time of the interview; she had begun her transition several years prior. She was a qualified social worker who was undertaking postgraduate research in the area of trans embodiment. When reflecting on her history of sexual relationships and on her transition from male-to-female, Marianna illustrated the distinctiveness of gender and sexuality categories, whilst simultaneously pointing to their intersubjective and mutually constitutive nature (Sedgwick 1990):

I knew that I was heterosexual. I've always been heterosexual. My heterosexualism hasn't changed. The only thing that's different is that I had more female partners to start with [when living as male] and I've got a male partner now [living as female].

5.3 Marianna articulated the changes that took place in her sexual identification and performance of roles in accord with her gender transition from male-to-female. In doing so, Marianna emphasised her perception of heterosexuality as the social norm and she positioned herself within the grand, or master, narrative of heteronormativity (Squire et al. 2014). Marianna said:

I wouldn't say I was bisexual because I'm not. My cultural upbringing was that I was a man therefore I had relationships with women.

5.4 By referencing her 'cultural upbringing', Marianna invoked a sense of collective identification (informed by hetero- and gender normativity) but also on a micro-level, the constraints of belonging. Anthias (2011) points out the importance of belonging as having experiential, practical and affective dimensions and, conceptually, it relates to how one feels about their location in the social world. In terms of Marianna's experiences of belonging, she firmly articulated this within the context of heteronormativity. By drawing upon the master narrative of heteronormativity as a cultural resource, Marianna also drew attention to the interplay of practices and belonging and enacted this through 'reflexive embodiment' (the ability to reflect upon and change bodily habits) (Crossley 2006; Williams et al. 2013).

In 1990 Butler persuasively argued for an alternative means of conceiving the confluence of gender and sexuality. She asserted that we do not simply perform gender and sexual roles which are predefined and fixed. Rather, the social categories of gender and sexuality (along with the correlated relations of power) are constantly deconstructed and reconstructed through our unthinking, iterative performances of gender. These performances of identity and role, Butler argued, are interpreted in accord with the hegemonic gender-normative and heterosexual matrix. Marianna achieved her sense of belonging through her practices and performances which aligned to this 'matrix' and dominant perceptions of gender and sexual identity. When she perceived her gender to have changed, Marianna then assumed a different sexual identity, reflecting the hegemonic dominance of heterosexuality but highlighting a problem in Butler's analysis as Marianna's performativity was agentic (that is, based on personal choice).

5.6 The conception of translocational positionality therefore opens up possibilities of identity and practice to be reflexive and unbounded. This helps to explicate the complex existence of a diversity of gendered positionalities and the interplay with sexuality, aesthetics and corporeality, and is particularly useful when these do not meet social norms and expectations. It does not, however, reduce gender and sexual positionality on these terms and acknowledges the centrality of context, meaning, experience and representation (Anthias 2011). Marianna highlights these elements when describing the first time that she dressed as a woman:

\footnotetext{
I looked in this mirror and it was like someone switching a light on in a room. I knew that was me, the real me in the mirror. I'd looked at myself in the mirror as a man, but there was never that connection whereas all of a sudden everything was coming into place. It knocked me for six.
}

Marianna's narrative demonstrates how translocational positionality represents a meso layer where positionality structures agency, but at the same time positionality is shaped by agency within the context of social structures.

\section{Mary}

5.7 Another participant, Mary (trans woman, aged 50) demonstrated agency within the context of her everyday life as the chief executive officer of a community-based LGBTQ organisation and both within her personal life. As with Marianna, Mary's narrative highlighted the interconnectedness and mutuality of gender and 
sexuality. When asked how she identifies, Mary referenced public and private contexts . Mary said:

Professionally, I identify as a post-operative transsexual woman who is bisexual. Personally, I identify as butch genderqueer, who occasionally does girly femme.

5.8 The construction of professional identity here shows a temporary alliance with the binary framework of gender and hetero/homo/bisexual triadic model of sexuality. Various theorists have argued that non-heterosexual identities are compelled to conform to these conventions in order to gain recognition (Sedgwick 1990; Butler 1990). Scott and Jackson (2006) go further to argue that all sexualities are positioned in a hierarchy in relation to heterosexuality where 'the normative status of heterosexuality is pivotal to the social ordering of both gender and sexuality' (Scott and Jackson 2006: 235). Mary provided additional context as to why she constructed her professional identity in this way:

When you're trying to present [your identity] to a bunch of cisgendered, heterosexual, white middle-class professionals, you try and introduce those concepts, they don't get it at all.

5.9 Mary invokes a sense of discontinuity by contrasting the normative positionalities of her professional colleagues with her own personal, non-normative identification. She does so to emphasise the lack of recognition and validation for gender and sexual identities which are deemed to be incongruent with those that are normative, binary and/or privileged. Consequently Mary points to the danger of uncritically drawing upon the theoretical analysis offered by Scott and Jackson (and others) which suggests that all sexual identity is positioned relative to heterosexuality, and this fails to acknowledge the potentiality of personal agency demonstrated in Mary's counter-narrative (Bamberg and Andrews 2004). In actuality, Mary demonstrates agency when discursively constructing both identities. In her professional narrative, Mary displays the 'political power' of positioning, and in her personal identity narrative Mary appropriates 'personal power' through the act of repositioning (Squire et al. 2014: 32). In this way, Mary's narrative illuminates how positionality is a social construction, and simultaneously constructs aspects of social location; this is the meso layer in operation.

5.10 As Mary demonstrates her capacity to mobilise across frameworks she shifts from a position understood in relation to the binaries of male/female and hetero/homo to one where both gender and sexuality are multidimensional. Mary sets her translocated positionality against the backdrop of the public/private divide and in doing so, she implicates the influencing nature of context. As each identity is contextually situated, and discursively demarcated by Mary ('professionally, I. . . personally, I...'), so her positionality translocates according to the parameters of acceptability and belonging within the public/private context in which she is spatially and metaphorically situated. Jenkins (2014: 18) would argue that this exemplifies how processes of identification reject fixity as identity is always in a state of 'being' or 'becoming'.

5.11 Whilst Mary's complex and translocated identification represents agency, however, through her discursive positioning as 'transsexual' and 'bisexual' in professional life, Mary is seen to demonstrate some degree of compliance, by identifying with category labels which are intelligible within the hegemonic binary framework of gender and sexuality (or, the master narrative). Indeed, Torre et al. (2001: 151) note how 'critical stories are always (and at once) in tension with dominant stories'. So, whilst Mary offers a 'resistant, counternarrative' in doing so she implicitly acknowledges dominant gender and sexuality frameworks (Bamberg and Andrews 2004; Squire et al. 2014: 33). She also borrows some of its components (identifying as a 'woman', and the butch/femme distinction), whilst rejecting others (through her positioning as 'genderqueer').

\section{Max}

5.12 One of the younger participants, Max (trans male/genderqueer, aged 25) was studying at university. Max had been assigned a female identity at birth but had come out as trans at the age of 24 despite for many years feeling that his female role was incongruous with other aspects of self. Max said:

I remember feeling male as far back as I can remember, and I remember at around six years old wishing that my body was the same as the bodies of the boys I hung out with, as I felt male in every other way.

As an adult Max identified his sexuality as queer, but offered a number of labels to describe his gender: In terms of my sexuality I identify as queer. In terms of my gender, I use a variety of labels depending on the context/options available. The most common term I use is trans ${ }^{*}$, however I also identify as male, genderqueer, FTM, MTM, queer.

Similar to Mary, Max highlights the multidimensional nature of terminology and discourse pertaining to trans. In Ekins and King's (2006: 184) taxonomy of trans identity and practice, by aligning himself with several labels, 
Max's narrative reflects 'a transcending story'; a personal narrative which 'problematize[s] this notion of personal identity'.

5.13 An alternative analysis may view Max's shifting and multiple identities as indicative of a transient phase in his transitioning during which Max explores gender and sexuality options in the quest for recognition (indeed, all participants articulated the desire for recognition and acceptance, many achieving this through performative work recognisable within the male/female binary framework (Butler 1990, 2004)). Prior to the onset of gender transitioning, Max had identified as a lesbian woman and had already engaged in a process of 'disidentification' with that community (Rubin 2003). A tension emerged, however, as Max was in a relationship with a cisgender, lesbian woman, Su. Max explained:

I was in a relationship when I came out as trans*. My partner at the time was honest with me about the fact that she doesn't feel as safe around men or around 'male' bodies, and that she may no longer feel safe around me as my physical transition progressed. This fed in to my already existing fear that my masculinity may be experienced as dominating or intimidating by my partner, and as a result I held back on expressing my masculinity around her.

5.14 Su found Max's male embodiment to be troubling, noting how she felt 'unsafe' (Max's maleness was not reflected in his material body, which still bore female physical traits). Max may have inclined towards a queer or genderqueer positionality to enable him to achieve some level of validation in his relationship with Su and subsequently he distanced himself from conventional forms of masculinity. Yet Max signified his preference for a male identity when indicating that he preferred the pronoun 'he' and that he, at times, identified as 'male' as noted above. Max's experience is not unusual as Williams et al. (2013) collected similar narratives in their study of trans men, embodiment and sexuality. Moreover, it is not uncommon for trans people to identify differently in sexual terms post-transition as a study by Rowniak and Chesla (2013) found that out of 17 female-to-male trans people after transition, ten identified as gay men and the remaining seven as bisexual/queer; prior to transition seven had identified as lesbian, three as heterosexual and seven as bisexual/queer.

\section{Rachel}

5.15 At 21 years of age, Rachel (genderqueer) was the youngest participant. Rachel was a student hoping to undertake research on trans issues and, as such, her ideas about gender were well developed; informed by both personal experience and academic scholarship. Rachel said:

I'd classify the [gender] spectra as relational, cognitive, behavioural, visceral and aesthetic.

Furthermore, unlike Max, who was seeking recognition, Rachel confidently articulated her positionality in terms pertaining to her identity, preferences, embodied practices and experiences. In doing so, she affirmed the fluctuating category of 'identity' (Segal 2008; Jenkins 2014) and described a more complex 'undoing' of gender, sex and sexuality (Butler 2004):

\footnotetext{
I identify as a male, intersex, lesbian woman (who fancies mostly men). The first two words refer to my visceral identity: I want a vagina as well, and feel as if it's missing, but I most likely wouldn't use it much! Then the latter two are the other bits; relationally I am a woman, but more like a lesbian or a tomboy than a heterosexual woman...I dress in a broadly-speaking feminine way, but with an unmistakably masculine edge, and this aesthetic appeals to me generally, as in I like bookish and geeky things, which is coherent with a masculine-version-of-femininity-typeaesthetic.
}

5.16 Rachel's reflexive narrative illustrates the considerable interplay between structure and agency within the meso layer as well as the value of translocational positionality as a conceptual lens. Indeed, Rachel constructs her identity revealing fluidity, mobility and temporality and does so in recognisable terms, albeit the construction offered by Rachel reconfigures gender, sexuality, corporeality and aesthetics in a unique way. Sweetman's (2003) notion of 'reflexive habitus' assists the analysis further as Sweetman uses this concept to argue that certain experiences, or groups, are more inclined towards reflexivity than others. Reflexive habitus implies constant mobility with respect to self-identity, positionality and performance (rather than in Bourdiesian terms where habitus is understood to be a static state rooted in early, classed experience). Rachel's selffashioning and translocated positonality makes use of cultural resources (discourses and representations) to offer a narrative identity consistent with Sweetman's notion of reflexive habitus. When considering other peoples' reactions to her, Rachel illuminates the workings of reflexive habitus:

\footnotetext{
...were I just a masculine male guy rather than a masculine chick with a dick, or whatever, they would fancy me, but dresses and make-up and frailty and feelings are turn-offs. And for others, they like me sexually in a fetishising way, rather than because they like me personally, even if that is also true.
}

Rachel's attention to practices of affect and desire, in the context of her gender/sexual identification, 
demonstrated her affiliation to a conception of gender and sexuality as complex intersecting spectra pertaining to the 'relational, cognitive, behavioural, visceral and aesthetic' (participant's words).

\section{Discussion}

6.1 The case studies above highlight the ways in which perceptions of gender and sexuality can be tied to normative, dualistic and fixed ideas about male/female and hetero/homo. The case studies also show how these perceptions can be problematised by the dynamic and reflexive capacity of trans identity and practice, and through agency and active embodiment. Notwithstanding, Scott and Jackson (2006) argue that all sexualities are positioned in relation with heterosexuality where 'the normative status of heterosexuality is pivotal to the social ordering of both gender and sexuality' (Scott and Jackson 2006: 235). In this configuration, gendered and sexualised positionalities are juxtaposed with heteronormative ideals, which are then embedded in a hierarchy which assigns different values to different positions. This claim is supported by Mary's experience of working across the public sector. The hierarchical system operates at a macro-level to reproduce and reinforce social structures and homeostasis, whilst at a micro level subjects are (re)produced to reflect hetero- and gender normative identities and roles.

However suggesting that all sexual identity is positioned relative to heterosexuality is rather deterministic. For example, Diamond's (2008) longitudinal study suggests that the dichotomisation of sexuality fails to capture the fluidity, diversity and exploration of sexual identification. Consider the sexuality of a trans person who has transitioned from one gender to live in another - a story of migration (Ekins and King 2006; Ahmed and Rogers 2016) - as this may remain unchanged, or this may alter to be an uncertain or a different position altogether (Aramburu Alegria 2010). So, a post-operative transsexual woman, like Jo, who entered marriage whilst identifying as a heterosexual, cisgender man, may continue to enjoy a sexual relationship with her wife following transition. Rather than now identifying as a lesbian, Jo may consider her sexual identity to be unchanged and therefore heterosexual (rather than homosexual which would reflect the embodied femaleness of both partners). This social location is constructed through a complex meeting of gendered and sexualised identities resistant to being reducible to normative and conventional positionalities, materiality and the corporeality of sex and sexual identity. In this imaginary scenario, the identities of each partner reject the supposedly preordained pairings of sexual identity (heter/homo) and the sexed body (male/female). Another participant, Jenny (trans woman, aged 64) highlighted this complexity when she considered "how does one identify who is biologically male, gendered female, and sexually attracted to female?" Therefore, the four case studies clearly draw attention to the changeable, 'rhizomatic' and potentially contradictory nature of positionalities found across the gender spectrum (Davy and Steinbock 2011: 268).

6.3 Before Scott and Jackson (2006) argued that all sexualities are socially positioned relative to heterosexuality, Foucault claimed that the individual is 'a parody: it is plural' (cited by McLaughlin 2003: 119). Similarly, drawing attention to the multiplicity of sexuality, Sedgwick (1990) mapped a range of sexual identities which transgress the heterosexual/homosexual/bisexuality triad through a denial of the centrality of bodily practices (genital sex) as a means of categorising gendered and sexual identities. Both Foucault and Sedgwick argue for a re-examination of the value and necessity of language and discourse which confine people to fixed and discrete social categories. The case studies presented here highlighted both the restrictions of language and labelling, but also of the possibilities for shifting positionality when different terms are adopted. Undoubtedly language and discourse represent powerful ways to govern and control people's lives and Sanger (2010) explored the ways in which trans people's sexuality is restricted and governed in the UK. This work led to her call for an 'ethics of intimacy... with respect to intimate lives through the reconsideration of regulatory frameworks of governmentality, and the expansion of thought to include a diverse range of intimate options' (2010: 134). Sanger suggests a reconfigured understanding of gender as a continuum to acknowledge and integrate various permutations of gender/sex/sexuality in the context of identity and embodiment relative to the practices and terms within human relationships. In addition, an understanding of these practices and boundaries should acknowledge the role of human agency in relation to positionality in order to consider:

'the social order of things, [and people's] views of where and to what [they] belongs (and do not belong), as well as understanding the broader social relations that constitute and are constituted in this process' (Anthias 2002: 512).

6.4 What these theorists share in common is a tendency to consider the structures which reinforce the mutuality of gender and sexuality, reflecting other dominant discourses and frameworks, such as diagnostic and medical ones (Steinbock 2014). A translocational lens helps to refocus on agentic power as marginalised individuals show creativity in their identity narratives and 'through strategies of diversion and evasion, they open up alternative spaces of identification' (Koefoed and Simonson 2012: 624). They are also creating new spaces of 
identification by drawing on multiple positionalities as a meso layer situated between agency and structure. For instance, whilst Marianna's narrative exemplifies heteronormativity and may, in this way, suggest a political strategy for representation, belonging and inclusion, other participants offer more explicit stories of resistance. In either case, an enhanced understanding of trans sexuality and subjectivity is enhanced within a translocated framing as this facilitates a narrative of mobility as well as compliance or transgression. Again, this is counter to a paradigm which sees the categories of gender, sex and sexuality as fixed, discrete and bounded.

\section{Conclusion}

7.1 Whilst interpreting trans people's narratives using the conceptual lens of translocational positionality, this paper offers an original contribution to the small body of literature on trans sexuality. The discussion shows that transgressions of gender normativity and heteronormativity are variable and materially, culturally, socially and spatially contingent (Hines 2010). Thus, analyses of trans sexualities benefits from a conceptual lens which shifts the focus on identity to examine the processes of social location, positionality and belonging (Anthias 2002, 2011). In addition, the co-constructed nature of narrative was highlighted to show the influence of agency, intersubjectivity, structure and positioning. Van Langenhove and Harré (1999: 17) emphasise the centrality of positioning in narrative as they assert that inevitably dialogue has 'story lines and the positions people take in a conversation will be linked to these story lines...whenever there are story lines, there are positionings'. Indeed, each case study signifies multiple positionings established through the participant's narrative practice and contextually understood in relation to existing structures. More importantly, as dialogue is an interactive site, it produces 'the empirical ground' through which identities come into existence (Bamberg 2004).

7.2 We argue that we have applied the conceptual lens of translocational positionality innovatively - it is mostly used within migration studies - to explore mobility as well as the limits and freedoms of coupling gender and sexual identification. By centring the paper on the four case studies above, we have shown how social location and positionality are enablers as seeing both as unstable and contingent facilitates an analysis of possibilities for trans people in different temporal and spatial contexts. As Anthias (2011) points out the value of looking at the processes of positionality is that this prompts us to consider positionality in a hierarchy within a time and space framework. Hence, Anthias reminds us not only of context, but also how social position is relational. More simply, Jenkins' (2014: 18, author's emphasis) asserts that 'one's identity - one's identities, indeed, for who we are is always multi-dimensional, singular and plural - is never a final or settled matter'. We bring attention to this dynamism through this paper's exposition of trans sexuality.

7.3 Finally, it is important to consider meaning-making and the claims that people make in their narrative practice. Indeed, Dargie et al. (2014) argue that there should be a focus on self-exploration and acceptance, rather than patterns of identification, as one of the findings in their study was that some participants identified as non-binary trans, or genderqueer, but simultaneously maintained a connection to the traditional gender role which they were ascribed at birth. Rather than dismiss these participants as individuals who have not yet fully transitioned, Dargie et al. argue that this underscores the multiplicities of gender and the often arbitrary nature of assigning specific gendered practices or qualities to a particular gender. Again, a translocated lens embraces the multidimensionality of gendered subjectivity to facilitate different positionalities. Thus, translocational positionality represents an inclusive conceptual device useful to investigations located in the vibrant and developing field of trans sexuality.

\section{References}

AHMED, A. (2013) 'Structural narrative analysis: Understanding experiences of lifestyle migration through two plot typologies', Qualitative Inquiry, Vol., 19, p. 232-243.

AHMED, A. (2015) Retiring to Spain: Women's narratives of nostalgia, belonging and community.Bristol: Policy Press. [doi:10.1332/policypress/9781447313304.001.0001]

AHMED, A. and Hall, K. (2016) 'Negotiating the challenges of aging as a British migrant in SpainGeroPsych, Vol. 29, p. 105-114.

AHMED, A. and Rogers, M. (2016) 'Polly's story: Using structural narrative analysis to understand a trans migration journey'. Qualitative Social Work. DOI:10.1177/1473325016664573. 
ANTHIAS, F. (2002) 'Where do I belong: Narrating Collective Identity and translocational positionality', Ethnicities, Vol. 2, No. 4, p.491-514.

ANTHIAS, A. (2008) Thinking through the lens of translocational positionality: an intersectionality frame for understanding identity and belonging. Translocations, Vol. 4, No. 1, p. 5-20.

ANTHIAS, F. (2011) 'Intersections and Translocations: new paradigms for thinking about cultural diversity and social identities', European Educational Research Journal, Vol. 10, No. 2, p. 204-217.

ANTHIAS, F. (2012) 'Hierarchies of social location, class and intersectionality: towards a translocational framing', International Sociology, Vol. 28, No. 1, p. 121-138. [doi:10.1177/0268580912463155]

ARAMBURU ALEGRIA, C. (2010) 'Relationship Challenges and Relationship Maintenance Activities Following Disclosure of Transsexualism', Journal of Psychiatric and Mental Health Nursing Vol. 17, p. 909-916.

BAMBERG, M. (2004) Positioning with Dave Hogan: Stories, Tellings, and Identities, in Dauite, C. and Lighfoot, C. (Eds.) Narrative Analysis: Studying the development of individuals in society. Thousand Oaks: Sage Publications Inc. [doi:10.4135/9781412985246.n23]

BAMBERG, M. and Andrews, M. (2004) Considering Counter-Narratives. Amsterdam: John Benjamins.

BARTOLUCCI, C., Gómez-Gil., E., Salamero, M., Esteva, I., Guilamón, A., Zubiaurre, L., Molero, F. and Montejo, A.L. (2015) Sexuality Quality of Life in Gender-Dysphic Adults before Gential Sex Reassignment Surgery. Journal of Sexual Meidcine. Vol. 12, p. 180-188. [doi:10.1111/jsm.12758]

BOCKTING, W.O., Benner, A. and Colemen, E. (2009) 'Gay and Bisexual Identity Development Among Femaleto-Male Transsexuals in North America: Emergence of Transgender Sexuality', Archives of Sexual Behavior, Vol. 38, p. 688-701.

BOLD, C. (2012) Using Narrative in Research. London: Sage. [doi:10.4135/9781446288160]

BUTLER, J. (1990) Gender Trouble: Feminism and the Subversion of Identity. New York: Routledge.

BUTLER, J. (2004) Undoing Gender. New York: Routledge.

CLANDININ, D.J. and Connelly, F.M. (2000) Narrative Inquiry: Experience and Story in Qualitative Research San Francisco: John Wiley \& Sons Inc.

COHEN, A.P. (1982) A sense of time, a sense of place: the meaning of close social association in Whalsay, Shetland, in Cohen, A.P. (Ed.) Belonging: Identity and Social Organisation in British Rural Communities. Manchester: Manchester University Press.

CORTI, L., Witzel, A. and Bishop, L. (2005) 'On the potentials and problems of secondary analysis. An introduction to the FQS special issue on secondary analysis of qualitative Data', forum: Qualitative social research, Vol. 6, No. 1, Art. 49, http://www.qualitative-research.net/index.php/fqs/issue/view/13.

CROSSLEY, N. (2006) Reflexive Embodiment in Contemporary Society. Buckingham: Open University Press.

DARGIE, E., Blair, K.L., Pukall, C.F. and Coyle, S.M. (2014) 'Somewhere under the rainbow: Exploring the identities and experiences of trans persons', The Canadian Journal of Human Sexuality, Vol. 23, No. 2, p. 60-74.

DAVY, Z. (2011) Recognizing transsexuals: personal, political and medicolegal embodiment. Farnham: Ashgate.

DAVY, Z. and Steinbock, E. (2011) 'Sexing Up' Bodily Aesthetics: Notes towards Theorizing Trans Sexuality, in S. Hines and Y. Taylor (Eds.), Sexualities: Past Reflections and Future Directions. Basingstoke, Palgrave Macmillan.

DIAMOND, L.M. (2008) Sexual Fluidity: Understanding Women's Love and Desire. Boston: Harvard University Press.

DOUCET, A. and Mauthner, N.S. (2008) 'What can be known and how? Narrated subjects and the Listening Guide, Qualitative Research, Vol. 8, No. 3, p. 399-409. 
ELLIOT T, H., Edwards, R., Phoenix, A. and Boddy, J. (2015) 'Narrative analysis of paradata from the Poverty in the UK survey: a worked example'. Southampton, GB, National Centre for Research Methods.

EKINS, R. and KING, D. (2006) The Transgender Phenomenon. London: Sage.

ENKE, A. (ed) (2012) Transfeminist Perspectives in and beyond Transgender and Gender Studies. Pennsylvania: Temple University Press.

FAUSTO-STERLING, A. (2000) Sexing the Body: Gender Politics and the Construction of Sexuality. New York: Basic Books.

GRACE, A.P., Cavanagh, F., Ennis-Williams, C. and Wells, K. (2006) 'Researchers' Positionalities and Experiences Mediating Lesbian, Gay, Bisexual, Trans-identified and Queer Research as a Personal and Cultural Practice', Auto/biography, Vol. 14, No. 4, p. 339-359. [doi:10.1177/0967550706072256]

HEATON, J. (2008) Secondary analysis of qualitative data, in P. Alasuutari, L. Bickman, and J. Brannen (Eds.), The SAGE handbook of social research methods. Los Angeles, Sage.

HINES, S. (2007) TransForming Gender: Transgender Practices of Identity, Intimacy and Care Bristol: The Policy Press.

HINES, S. (2010) 'Queerly situated? Exploring negotiations of trans queer subjectivities at work and within community spaces in the UK', Gender, Place \& Culture, Vol. 17, No. 5, p. 597-613.

HINES, S. (2013) Gender Diversity, Recognition and Citizenship: Towards a Politics of Discourse.Basingstoke: Palgrave Macmillan. [doi:10.1057/9781137318879]

HOLSTEIN, J.A. and Gubrium, J.F. (2000) The self we live by: narrative identity in a postmodern world.New York: Oxford University Press.

HUBBARD, G. (2000) 'The usefulness of indepth life history interviews for exploring the role of social structure and human agency in youth transitions', Sociological Research Online, Vol 4, No. 4, http://www.socresonline.org.uk/4/4/hubbard.html. [doi:10.5153/sro.390]

IANTAFFI, A. and Bockting, W.O. (2011) 'Views from both sides of the bridge? Gender, sexual legitimacy and transgender people's experiences of relationships', Culture, Health and Sexuality, Vol. 13, No. 3, p. 355370.

JACKSON, S. (2006) 'Gender, Sexuality and Heterosexuality: the Complexity (and Limits) of Heteronormativity'. Feminist Theory, Vol. 7, p.105-121. [doi:10.1177/1464700106061462]

JACKSON, S. and Scott, S. (2001) Putting the Body's Feet on the Ground: Towards a Sociological Reconceptualization of Gendered and Sexual Embodiment, in Backett-Milburn, K. and McKie, L. (Eds.) Constructing Gendered Bodies. Basingstoke: Palgrave.

JENKINS, R. (2000) 'Categorization: identity, social process and epistemology'.Current Sociology, Vol. 48, No. 3, p. 7-25. [doi:10.1177/0011392100048003003]

JENKINS, R. (2014) Social Identity (4th edn). Abingdon: Routledge.

KESSLER, J. and McKenna, W. (1978) Gender: An ethnomethodological Approach. New York: WileyInterscience.

KOEFOED, L. and Simonsen, K. (2012) '(Re)scaling identities: embodied others and alternative spaces of identification', Ethnicities, Vol. 12, No.5, p. 623-642.

MAY, V. (2013) Connecting Self to Society: Belonging in a World Basingstoke: Palgrave Macmillan. [doi:10.1007/978-1-137-36726-6]

MCCLENNEN, J.C. (2003) 'Researching Gay and Lesbian Domestic Violence: the Journey of a Non-LGBT Researcher', in Meezan, W. and Martin, J.I. (eds.) Research Methods with Gay, Lesbian, Bisexual and Transgender Populations. New York: Harrington Park Press.

MCLAUGHLIN, J. (2003) Feminist Social and Political Theory: Contemporary Debates and Dialogues.

Basingstoke: Palgrave Macmillan. [doi:10.1007/978-0-230-62956-1] 
MONRO, S. (2007) 'Transmuting Gender Binaries: the Theoretical Challenge', Sociological Research Online, Vol. 12, No. 1, http://www.socresonline.org.uk/12/1/monro.html.

MONRO, S. and Warren, L. (2004) 'Transgendering Citizenship',Sexualities, Vol. 7, No. 3, p. 345-362. [doi:10.1177/1363460704044805]

NAGOSHI, J.L., Bruzy, S. and Terrell, H.K. (2012) 'Deconstructing the complex perceptions of gender roles, gender identity, and sexual orientation among transgender individuals', Feminism \& Psychology, Vol. 22, No. 4, p. 405-422.

PERSHAI, A. (2006) 'The language puzzle: is inclusive language a solution', in Scott-Dixon, K. (ed.) Trans/Forming Feminisms: Trans/Feminist voices speak out Toronto: Sumach Press, p. 46-52.

PFEFFER, C. (2014) 'Making space for trans sexualities'. Journal of Homosexuality, Vol. 61, p. 597-604.

PINI, B. (2004) 'On being a nice country girl and an academic feminist: using reflexivity in rural social research'. Journal of Rural Studies, Vol. 20, No. 2, p.169-179. [doi:10.1016/j.jrurstud.2003.08.003]

PROSSER, J. (1998) Second Skins: The Narratives of Transsexuality. Columbia University Press, New York.

RIESSMAN, C.K. (2008) Narrative Methods for the Human Sciences. London: Sage.

ROGERS, M. (2013) 'TransForming Practice: Trans People's Experiences of Domestic Abuse and Social Care Agencies', PhD Thesis, Sheffield, University of Sheffield.

ROGERS, M. (2016a) 'Breaking down barriers: the potential for social care practice with trans survivors of domestic abuse'. Health and Social Care in the Community Vol. 24, No. 1, p. 68-76. [doi:10.1111/hsc.12193]

ROGERS, M. (2016b) 'Transphobic 'honour'-based abuse: a conceptual tool'.Sociology. DOI: $10.1177 / 0038038515622907$.

ROWNIAK, S and Chesla, C. (2013) 'Coming Out for a Third Time: Transmen, Sexual Orientation and Identity', Archive of Sexual Behavior, Vol. 42, p. 449-461. [doi:10.1007/s10508-012-0036-2]

RUBIN, H. (2003) Self-made men: identity and embodiment among transsexual men. Nashville: Vanderbilt University Press.

SANGER, T. (2010) Trans People's Partnership: Towards an Ethics of Intimacy. Basingstoke: Palgrave Macmillan. [doi:10.1057/9781137082220]

SCHILT, K. and Westerbrook, L. (2009) 'Doing Gender, Doing Heteronormativity: "Gender Normals" , Transgender People, and the Social Maintenance of Heterosexuality', Gender \& Society, Vol. 23, No. 4, p. 440-464.

SCOTT, S. and Jackson, S. (2006) Sexuality, in Payne, G. (Ed.)Social Divisions (2nd edn). Basingstoke: Palgrave Macmillan. [doi:10.1007/978-1-137-08868-0_10]

SEDGWICK, E. (1990) Epistemology of the Closet. Berkeley: University of California Press.

SEGAL, L. (2008) After Judith Butler: Identities, who needs them?Subjectivity,Vol. 11, p. 1-14. [doi:10.1057/sub.2008.26]

SERANO, J. (2007) Whipping Girl: A Transsexual Woman on Sexism and the Scapegoating of Femininity. Berkeley: Seal Press.

SHAW, I. and Holland, S. (2014) Doing Qualitative Research in Social Work. London: Sage. [doi:10.4135/9781473906006]

SQUIRE, C., Davis, M., Esin, C., Andrews, M., Harrison, B., Hyden, L. and Huden, M. (2014)What is Narrative Research? London: Bloomsbury.

STANLEY, S. and Billig, M. (2004) Dilemmas of Storytelling and Identity, in Dauite, C. and Lighfoot, C. (eds.) Narrative Analysis: Studying the development of individuals in society. Thousand Oaks: Sage 
STEINBOCK, E. (2014) 'Pornography', Transgender Studies Quarterly, Vol. 1, No. 1-2, p. 156-157.

STONE, S. (1987)'The Empire Strikes Back: A Posttranssexual Manifesto, in Epstein, J. and Straub, K. (eds.) Body guards: The cultural politics of gender ambiguity. London: Routledge.

SWEETMAN, P. (2003) 'Twenty-first Century Dis-ease? Habitual Reflexivity or the Reflexive habitus', Sociological Review, p. 528-49.

TALBOT, M. (2010) Language and Gender(2nd edn). Cambridge: Polity Press.

TEMPLE, B. (2001) 'Polish families: a narrative approach'. Journal of Family Issues, Vol.22, No.3, p. 386-99.

THORNE, S., E (1994) 'Secondary analysis in qualitative research: issues and implications', in J. M. Morse (Ed.), Critical issues in qualitative research methods. London: Sage.

TORRE, M. et al(2001)' A space for co-constructing counter stories under surveillance',International Journal of Critical Psychology. Vol. 4, p. 149-66.

WARNER, M. (1991) Fear of a queer planet. Minneapolis MN: University of Minnesota Press.

WEST, C. and Zimmerman, D. (2009) 'Accounting for Doing Gender', Gender \& Society, Vol. 23, No. 1, p. 112122.

WHITTLE, S. (2006) 'Foreword', in Stryker, S. and Whittle, S. (eds.)The Transgender Studies Reader. New York: Routledge.

WIERCKX, K., Van Caenegem, E., Elaut, E., Dedecker, D., Van de Peer, F., Toye, K., Weyers, S., Hoebeke, P., Monstrey, S., De Cuypere, G. and T'Sjoen, G. (2011) Quality of Life and Sexual Health after Sex Reassignment Surgery in Transsexual Men. International Society for Sexual Medicine. Vol. 8, p. 33793388.

WILCHINS, R. (2004) Queer Theory, Gender Theory: An Instant Primer. Los Angeles: Alyson Publications.

WILLIAMS, C.J., Weinberg, M.S. and Rosenberg, J.G. (2013) 'Trans Men: Embodiments, Identities, and Sexualities'. Sociological Forum, Vol. 28, No. 4, p. 719-741. 